\title{
Organization of Activities and Management in Starting Software Firms
}

\author{
$\mathrm{PhD}$ candidate Svetoslav Ivanov \\ University of Economics - Varna, Varna, Bulgaria \\ svetoslav_ivanov@ue-varna.bg
}

\begin{abstract}
Companies achieve their goals through the management function organization for the people and resources to achieve their goals. The starting software companies have a specific goal for a new product. There are various definitions for a new product and goal. We will review starting software companies which target to develop a new product and validate it on a market for vitality and growth potential. Their need for function organization is specific. The current article aims to do a theoretical review for the methods of organization of activity and management of the company in its early stages.
\end{abstract}

Keywords: organization, management, starting company, software company, entrepreneurship

JEL Code: O32; doi:10.36997/IJUSV-ESS/2019.8.3.196

\section{Introduction}

Information technologies (IT) development and the effect on business drive their implementation in various sectors and functions of the business. Their role moves from supporting one to a key factor in the business. IT allows implementing the digitalization of parts of the business, which changes the processes in companies and even the type of business or the way the business operates. Two key components are in this process - the software and the innovation process. It is well known the boom in the software industry and entrepreneurship in software development, how many failures happen due to inappropriate management of the innovation process or the starting business. To make sure these initiatives are successful and sustainable, they should be accepted by the market and the business to be vital and profitable. Also, the starting software companies are established and managed by entrepreneurs. To achieve the goal for market acceptance and grow, they should answer some fundamental questions about "How we make money in this business? What is the underlying logic that explains how we can deliver value to the customer at an appropriate cost?" (Magretta, 2002). To answer these questions, the entrepreneurs should find and implement appropriate business models, so the new product or service they invent to be successful. To answer these questions, to find an appropriate business model and validate it, all should be and usually created by organization. The people, the activities, the resources need to be organized to achieve the goal. This is achieved by creating an organization with its goal, structure, functions and components. The literature of general management, entrepreneurship, software development management in particular and start-up management could give the appropriate approaches.

In this article, the purpose is to review the most common theoretical concepts for business organization appropriate for starting software companies. To achieve this goal, we define the tasks for the paper - definition of the subject - starting software company, define the terms "business model", "organization" and "software product", as well as review the theoretical concepts for creating organization in two subtasks - the general concepts and specific ones appropriate for the subject starting software companies.

\section{Definition of Starting Software Company}

The key object of this article is the term "starting software company". By the means of the name, this term belongs to the terms "starting technology company", "technology start-up", "software company", "start-up", "small and medium enterprise", etc. The legal base in the European Union and Bulgaria uses the term "enterprise" and separates the enterprises in four categories. They differ according to the company size measured as number of employed people and annual turnover or the 
value of assets. The target term is in the group of SME (micro, small and middle enterprises), but we will focus on a more tight group - micro and small enterprises - under 50 employees and less than 10 million Euro turnover or assets (European Commission, 2019). Alternative approaches are to measure the stage/amount of investment or the simpler one "before becoming big company" (Blank, 2013), which is equivalent to the criterion for size. Another important and simple to measure criterion to specify the companies, it is the age measured as time since company establishment. The short cycle of innovation and technological development lead us to select a period of fewer than 5 years.

The third criterion defining the company is based on the key goal in the business - to develop a new product, to apply a business model, to prove vitality and potential growth. The definition for a start-up from this point of view is "a company or project initiated by an entrepreneur to seek, effectively develop, and validate a scalable business model" (Ries, 2011). Similar and related goals are to reach satisfactory product-market fit, to develop customer base where the focus is on searching clients, adapting the product and business model that fits the market (so-called Customer Development Model) (Blank, 2013). Another formulation of the same goal we could find having in mind that such companies may target new markets. The new markets are characterized by low structure, high unpredictability, and limited understanding of customers, rivals and market segments (Santos and Eisenhardt, 2009). "It seems likely that moves that explore the market for opportunities - rather than moves that exploit existing positions - are particularly key" (Katila et al., 2011). This leads us to the next statement, that an established company focus on exploiting existing positions, or in other words uses Product Development Model to optimize the processes and structures for established products and markets. This criterion is the most important one for the distinction between a starting and an established company.

In the literature can be found different forms of entrepreneurial activity. In this article, we will skip the starting companies which plan or behave to stay small - freelancers, lifestyle, small family or service businesses. Also, we will add the definition "search for growth or scalable model" (Blank, 2013; Ries, 2011). Therefore, we will skip also entrepreneurship that copies or reuse a ready product, business model, and brand at a high level like a franchise, business acquisition, etc. As a fifth criterion, we will focus on a model with own product and business model. Even when it uses third party components, a known business model, the company has at some level unique product, model, brand, etc.

Including the word "software" in the term shows that the company is going to develop technological product software. In this article, we will use a technology company in the means to produce a technological product. In the literature, there are sufficient definitions for the term "software", it's content and development, therefore, we will not review all of its specific features.

Finally, a starting company is initiated by one or more entrepreneurs. We will use the term entrepreneur for a single entrepreneur or a team of entrepreneurs who initiate and lead a starting software company. There are researches (Davidsson, 1989; Storey, 1994) that describe and prove that the main factor for SME company success and growth is connected to the entrepreneurs and their personal goals, motivation, orientation to market, capability for growth, and professional management. Therefore, the entrepreneur is a key factor. Connecting this to the article's goal, this leads to the next reason for importance concerning the article because the knowledge for and successful implementation of an appropriate business organization is a factor for company success.

After all these definitions we could summarize that a starting software company is a new micro or small company up to 5 years old, founded by one or team of entrepreneurs that develop a new software product and search business model that proves feasibility, vitality and product-market fit with growth potential. Such companies may differ in the business model, strategy, processes, product, team, entrepreneur, type of product (product, service, platform, component, solution), customer-driven or technology-driven, etc. We will not review them in details but will focus on the organization approaches.

The next term we need to specify is "product". In this paper, we use a more general meaning 
of product as a result of company activity. Often in the literature for innovations, entrepreneurship, start-ups, business modeling there are used different terms like product (Ries, 2011), solution, unique proposition (Maurya, 2012), service, customer value (Blank, 2013; Poppendieck et.al., 2003), etc. We use the term "product" as a result of the innovation process for a starting software company. A similar definition is "Anything customers experience from their interaction with a company should be considered part of that company's product" (Ries, 2011, p.38). In this article, the term product is a more abstract term that is closer to the last definition and summaries the various forms of what customer experiences interacting with the company - concrete product, solution, service, value, technological innovation, etc. based on innovation with or connected to a product with IT technologies. The terms technology is defined as "knowledge, skills, and artifacts, which could be used for the development of products and services, as well as their production and delivery systems" (Burgelman, 2004). The term "innovation" we use in the meaning of product as a result from innovation process that is realized on the market. The important distinction here is that the innovation is technology realized in a product on a market. Some ways to do this is through the optimization, change or components change of existing systems, products and structures (Burgelman, 2004).

The starting software company is defined by the result - the software product. The software has specific features described in the literature as a product concerning both the production and support of software. We will mention some of them (Eskenazi and Maneva, 2006; Panayotova et al., 2016; Petrov et al., 2018; Poppendieck, 2003):

- Fast development in IT and software technologies require short releases.

- Product complexity - various vendors of platforms, components, tools, etc.

- Quality is a complex term - features, security, scalability, performance, user experience, robustness, integration with 3rd-party software, and others.

- High-quality requirements - increasing quality requirements over time, extensive quality assurance procedures, security audits, etc.

- Requirements - not clear initially, need discovery, may change over time.

- Serious investment before first working or marketable copy.

- Multi-disciplinary - requires the participation of various specialists.

- Product defects share in all copies of the product.

- The high price of software development specialists.

- There is extensive work with knowledge and a need for constant learning.

- Must work on various devices, platforms, browsers, servers, etc.

- Regular upgrades - because of component changes, technology changes, bugs, security threats, legal, etc., the product needs regular upgrades.

- Available support - the product requires available support service.

- Quality or time of delivery could be a critical problem

- Specific licensing rights to meet and keep.

Therefore, the process of software product development should reflect these changes. Two key concepts in successful software development are user involvement and requirements description and stability. For starting software company this is not the case - it works often under uncertainty. Initially, the user or customer may not be clear, requirements may change during the search of the market niche fit. The feedback is not always direct - asking questions about getting the answer. It might need an analysis of data, experiments to validate a supposed requirement. Every supposed requirement needs business analysis for the financial and marketing effect of its application.

\section{Definition of business model and organization}

The market success of a product can be realized with a specific business model. The term "business" means a sustainable organizational structure whose purpose is the return on investment (Scarborough, 2013). The term "model" is defined in the literature, and a popular definition is that a 
model represents the real object in an abstract way or phenomenon to show its essence, characteristics, dependencies, interactions by using a language for model description (Eskenazi and Maneva, 2006, p.31-32). The combination of both terms is our focus on the term "business model". It is first defined by Peter Drucker as "the assumptions on which the organization has been built ... the assumptions that shape any organization's behavior, dictate its decisions ... the assumptions about markets, identifying customers and competitors, ... technology and its dynamics, about a company's strengths and weaknesses, ... about what a company gets paid for" (Drucker, 1994). In the literature of management and entrepreneurship could be found many definitions for business model. For our article we will refer these:

- "Describes the rationale of how an organization creates, delivers, and captures value" (Osterwalder and Pigneur, 2010).

- "Refers to the core architecture of a firm, specifically how it deploys all relevant resources (not just those within its corporate boundaries) to create differentiated value for customers" (Tapscott et.al., 2000).

The definitions show that the business model is the integration of decisions and representation of the business logic to provide competitive advantage and market realization of the innovation based on relevant resources. At the same time, it must keep the company a sustainable structure and to assure return on investment (often expressed with terms like make money, generate revenue, make a profit, etc.). The business model is connected to the business strategy, it is dedicated to a product and this determines the component competitive advantage. On the other hand, the strategy is usually for the company and does not determine the other components of the business model. The "business models describe, as a system, how different pieces of a business fit together. But they do not factor in one critical dimension of performance: competition". The "strategy explains how you will do better than your rivals" (Magretta, 2002). The development of a business model is part of the innovation process and is key for the business success.

As every model, a business model could be described with its components. The components determine various sides of the business, the value it creates and delivers. The key components to be addressed (Osterwalder and Pigneur, 2010; Maurya, 2012; Mullins and Komisar, 2013):

- Value Proposition - the products, services, solution, competitive advantage.

- Problem and solution - customer-driven problem and solution for it.

- Market - customer segments, specific structures of the industry, distribution, channels.

- Value creation - resources, activities, processes, structures, partner networks.

- Costs - the costs to create product (value), deliver it and operation.

- Revenues - how the company is getting paid for the value it delivers.

- Company position - core competencies and the position in business networks that is the place in the whole network of value delivery chain and partnerships with other organizations in the markets (Tapscott et al., 2000).

The business models could be classified by various criteria and described as different categories. Many authors propose their own classification for the business models appropriate for software companies. For example, a more abstract classification is given from Tapscott according to value integration and economic control - agora, aggregation, value chain, alliance, distributive network (Tapscott et al., 2000). A more concrete classification is proposed from Timmers - e-Shops, e-Procurement, e-Malls, e-Auctions, Virtual Communities, Collaboration Platforms, Marketplaces, Value Chain Integrators, Value Chain Service Providers, Information Brokerage, Trust and Other Third Parties (Timmers, 1998). There exist many other classifications and entrepreneurs may use for the business organization any of these as a base to build their own with specific details and parameters. This way, the business model defines the key assumptions, rules and parameters according to which the organization should interact with the market and to make sure the products are vital on the market with growth potential.

The definition of the business model gives a structure for interaction mostly between the 
company, the market and other partner organizations. To realize it the entrepreneurs, need to create their organization. The management theory states that the organization is a needed "system of intentional coordinated activities of two or more people to achieve a common goal" (Robins De Cenzo, 2008). Therefore, the entrepreneurs need to do the managerial work to create an organization. It means to design, implement and support an organizational structure to achieve the goals. Within they should execute the management functions - planning, organizing, execution, control. The function "Organizing" is to create the structural components of the organization. It is defined as a process of modelling the structure of tasks, powers, people and communications to coordinate efforts to achieve the goals and strategies of the organization. Therefore, the focus of the article is on the organization as a business structure and management function.

\section{Business organization structures}

First, we will discuss the organization as a business structure. It is aimed to reach goals from many people. An organization has a formal and informal structure. The formal structure determines the constant relationship between their elements, the power share and responsibility for taking decisions. The main principle in formal structures is the hierarchical relationship between the centers for taking decisions. As Peter Drucker states every organization needs to have highest power and the hierarchical structure is criticized, but it is a must and must be accepted by all members of the organization in situations of crisis (Drucker, 2001, p.73-87). The system of formalized tasks and power relations form the base frame of formal control. It is usually drawn with a diagram for organizational schema. When the organizational structure is designed, there should be done three sequences of activities (Daft, 2002):

- Horizontal division of labor - decide how to separate work between functional blocks and people. It is connected to the level of work specialization.

- Vertical division of labor - decide how to share the official power, power relations between positions and structural elements, as well as the chains of power and responsibility.

- Integration and coordination - mechanisms to integrate and coordinate the work of different structural elements and people.

Using the above principles and decisions, an organizational structure is relatively constant order between structural elements and their relations. The connections between the elements could be relations of a subordination or relations of equality. Also, the relationships could be structureforming and relationships for communicational channels (Daft, 2002; Cole, 1993). The structuredetermining relations for forming the departments and units could be developed with one or a combination of the following principles (Daft, 2002; Donnelly et al., 1992; Griffin, 1990):

- Linear (hierarchical) - a group of people is subordinated to a manager. No specialization for the managers.

- Functional - grouping people based on the common specialization and competencies.

- Divisional - grouping people based on product or geographical principle (by product, by location/region).

- Program/Project - grouping for a given program, project or goal.

Using these principles, in the management theory (Daft, 2002; Donnelly et al., 1992) there are described the typical standard known organizational structures. They are well described with their specifics, advantages and disadvantages. We will focus on a brief summary.

The first structure is the linear organizational structure, known also as a standard pyramidal hierarchical structure. It has a linear chain of command and control from top level to lowest level. Very typical is the single source of commands and reporting. The chain of command and accountability is followed strictly. The positive side is the clearness of commands and responsibility, the linear managers have strong power within their subordinated department and all the organization can follow the same policy and orders. In negative side, they could show up the negative side of the 
bureaucracy, long wait of decisions and orders, slow reaction, large amount of written documentation, hard collection of information, etc. (Griffin, 1990; Donnelly et al., 1992). The linear structures are appropriate for small companies, starting business and business units for production - where products are manufactured/services are created.

The second structure is functional organizational structure. It is one of the most common types of organizational structures. The functional structure departmentalizes an organization based on common job functions and would group all of the same specialists together in one department and each group of specialists will have own department. Functional similarity is key principle. Their manager should have the same technical/functional specialization and have command power within this competency. The functional structure allows for a high degree of specialization for employees and is easily scalable when the organization should grow (Griffin, 1990; Donnelly, 1992). This structure is mechanistic and has the potential to inhibit an employee's growth. It puts the staff in skillsbased departments and allows them to develop deep into their field and what they're good at. It is good for large scale businesses with a limited number of products or modifications. At the same time, the negative side is that there is no clear responsibility, mix of commands from different sources and the potential to create barriers between different functions, to be inefficient when the organization has products variety or target market variety. The barriers created between departments can also limit peoples' knowledge and communication with other departments, especially those that depend on other departments to succeed. Also, there are problems with the coordination and conflicts from different commands coming from different managers and the "tasks to resolve conflicts" from top management.

To resolve some problems of functional structure, one alternative is a modification to the linear structure with functional consulting unit. It consists of functional specialists, who consult the linear manager without taking decisions or give commands. The final responsibility for decisions is for the linear manager being consulted. It is widely implemented in organizations from the small and medium business with various specialists in the consulting unit. They raise the competency of the manager, with the risk of potential conflict to ignore advices and take full responsibility. One alternative of the consulting unit is to hire external organizations to do services for the company and under the control of the responsible manager in the organization (i.e. to hire agencies to do some job like marketing, accounting, services, human resources hiring, etc.). An alternative is the manager's personal assistant. A third alternative is that the functional consulting specialists to have some permissions for command, approval of final decisions from functional specialists according to their competencies (Donnelly, 1992; Robins and De Cenzo, 2008).

The fourth structure is a combination between linear and functional structure, where the linear structure exists, but also there is functional one that has a limited power to give commands and request reporting just into their competency. There are two different variants with more or less competencies and power for functional departments to linear managers and their subordinates. This kind of structures are good for middle and large businesses. Their positive side is raising the competency of command, speed up the process of information flow to take decisions and the strengths of linear managers. At the same time, it complicates the relations between departments and specialists, potential conflicts between commands, closing of functional units into their goals and to lose priority of the company goals (Robins and De Cenzo, 2008).

To resolve some problems of functional and linear structure when the business grows geographically, with markets or products, the third structure - divisional structure appears a better choice. The divisional organizational structure is comprised of multiple functional structures or separate business units (i.e. each division has all functional departments/teams into it). In this case each division within the organization dedicates to a particular group. The division by groups can be done by product - product-based divisions. It is ideal for organizations with multiple products and can help the organization to be agile, shorten product development cycles, and adaptable to changes from the environment with quick reaction. It allows to companies and business units better specialize 
in a given product or market. It eases the coordination, quickly taking decisions and resolving conflicts between functional departments. It separates the top management from resolving divisionlevel conflicts and focus on strategic decisions. This allows small businesses to go to market with new offerings fast or large organizations to be more flexible. The disadvantages are that it can be difficult to scale under a product-based divisional structure, and the organization could end up with duplicate resources as different divisions strive to develop new offerings. Also, there could be competition between divisions for importance, resources or competition in product sales (Booth, 1993; Robins and De Cenzo, 2008; Donnelly et al., 1992).

A modification of the divisional structure is market-based divisional structure. The marketbased structure is ideal for an organization that has products or services that are unique to specific market segments or different marketing segments need different approach. It is particularly effective if that organization has advanced knowledge of those segments. This organizational structure also keeps the business constantly aware of demand changes among its different audience segments. But it could lead divisions to develop systems incompatible with one another and duplicate activities. It has similar advantages/disadvantages as the product-based structure.

Another modification is the geographically-based divisional structure. The divisions respond for different regions, different countries, cities. It allows to quickly and better react to local specific market, customers, requirements; to be near the sources of supply or customers. It brings the business expertise but allows each division to make decisions according to local conditions. It is similar to market-based in advantages and disadvantages - competition for resources, duplication of specialists, coordination problems, competition between divisions, a great deal of autonomy.

The above structures are called "mechanistic". They are thought as structures that are limited in capabilities for adaptation to fast changes in the environment. Therefore, Burns and Stalker define organistic organizations to be adaptable to the external environment changes. According to them in such structures there are informal horizontal relations of power and free vertical and horizontal communications. There exist many specialists with high engagement to their tasks (Booth, 1993). The first kind of such a structure is the project-based structure. It is realized over the usual structure, where, temporary a team of specialists and project manager is built for the project goal and for the time the project is executed. The advance is the focus, the concentration of attention, to the project both the project manager and specialists are focused on the project, only. The project participants are subordinated only to the project manager for the project time. It is appropriate for large projects or for small projects there is adaptation. Usually, it is an expensive structure (Booth, 1993).

The other adaptable structure is the matrix structure. It is like a matrix, where the rows are different projects and the columns - the traditional departments from linear-functional structure. The project managers power may vary. Usually they are meant at the same power as linear managers and subordinated to top management (Stone and Freeman, 1992). The specialists have two managers project manager and department manager and dual reporting relationships. The department manager is responsible for the development of the specialists in his department, training, rewarding, motivation - the functional reporting line. The project manager is responsible for project goals, tasks, resources, project plan, and project execution - the project-based reporting line. The advantages of matrix structure are the better coordination between specialists, information flow, higher importance of the horizontal relations. The matrix structure can provide both flexibility and more balanced decisionmaking (as there are two chains of command instead of just one). Having a single project overseen by more than one business line also creates opportunities for these business lines to share resources and communicate more openly with each other (might not be able to do regularly). The disadvantages are in the complexity, the more layers of approval, conflicts from different subordination, burning overloaded specialists, conflicts from the difference in the priorities between projects, between departments, and between project and department tasks. Also, there might be confusion in a situation of crisis - who is responsible for decisions. One way to overcome is to organize groups and meetings to resolve conflicts, which is expensive. 
The modern challenges require new structures that are more adaptable to the changes, improved communication and increased role of horizontal communication. One approach in this direction is the flat structure (Kreitner, 2009). A more traditional organizational structure might look more like a pyramid with multiple levels of managers between staff and leadership, the flat structure limits the levels of management, so the staff is closer to the top leaders. It also might not always take the form of a pyramid, but any other shape for the case. This structure is probably the most detailed and employees could be more productive in an environment with less hierarchy-related pressure, the staff feels the managers are more like equals or team members. The disadvantages are that in case of disagreement on something, it can be hard to get aligned without executive decisions from a manager. Because of how complicated the structure's design is, it can be hard for an employee to determine which manager can take decision for a problem or to ask for an approval. So, having a flat organization requires to have a clearly marked tier of management or a path that employers can refer to when they run into these scenarios (Kreitner, 2009).

A more improved form of flat structure is the cluster or team-oriented structure. There, the middle managers level is removed, because the information flow is provided by information systems. The managers have broader competency and need more horizontal communications to take decisions. The employees have higher power for decisions. The teams are the main structural unit and the accent is on team work together of multi-functional specialists. They may change the teams according to the project requirements. One of the ideas here is to get highly qualified with deep knowledge and highlevel competencies. These organizations have a variant with ad-hoc structures for non-standard and complex projects. The accent is no low-level hierarchy, horizontal communications, increase of the power of having specific knowledge and skills, staff with expert level. The advantages are that these structures could achieve exceptional results and preserve adaptability (Smith, 2007).

Another improved form of adaptable structure are the network and virtual structures. With the internet technologies, the focus in the organization is not only to create, produce and sell the products, but to have the speed to do this. The faster the organization is in this cycle, the better it could react to the changing conditions in the environment. An approach in this direction is to use external organizations for some of the functions to do this better and faster instead of development of internal functional departments or support functional specialists. Also, the organizations may participate in a network of partnerships to focus better on core business tasks and to rely on partners and business networks for other non-core activities. Such organizations describe Tapscott and gives classifications, definitions of networks and partners (Tapscott, 2000).

A network structure is often created when a company works with another to share resources or opportunities as value for the first one. For example, when a company has multiple locations with different functions and leadership. It may provide them to third organizations. Another option is to implement company workflows with staffing and services that are outsourced to freelancers or multiple other businesses. This way, creating horizontal connections with collaboration and coordination, they replace the formal lines of power. Through outsourcing of many secondary and some primary functions to subcontractors, the entrepreneurs and their assistants could focus in one central office to the organization, communication and coordination (Smith, 2007). The core idea is to focus only on activities, where the company is best and give the other activities to other companies, where they are best. The disadvantage is that if the model complicates, there may be a lot of confusion and duplication between multiple offices or multiple freelancers to do similar things, misunderstand for the role and job function of unclear or complicated company's processes.

A variant of the network structures are the virtual structures. They upgrade the network structures with implementation of information technologies and keeping the connections virtual. The projects are done with temporary groups of people to do given project, who are not part of the organization. The communication and the information flow are via electronic channels. Often, businesses do the processes virtually to organize and control the process flow with virtual instruments and outsource the physical operations. Vice versa, many organizations propose such services to 
companies, to use virtual tools so they could organize their business or some functionality (Tapscott et al., 2000). Another initiative is to reorganize the departments, so they change the way some functions are done, implement informational and web technologies. The process of digitalization of the business requires restructuring of processes, jobs, units, departments. For example, financial departments use new electronic methods for payments and banking, marketing for the research, advertisement and sales, human resources for recruitment and hiring of specialists (Daft, 2002; Smith, 2007).

The circular structure appears drastically different from the other organizational structures. It relies on hierarchy, with higher-level employees occupying the inner rings of the circle and lowerlevel employees occupying the outer rings. The leaders or executives in a circular organization aren't seen as sitting on the top of the organization, sending directives down the chain of command. Instead, they're at the center of the organization, spreading their vision outward. A circular structure is meant to promote communication and the free flow of information between different parts of the organization. Whereas a traditional structure shows different departments or divisions as occupying individual, semi-autonomous branches, the circular structure depicts all divisions as being part of the same whole. From a practical perspective, the circular structure can be confusing, especially for new employees. Unlike with a more traditional, top-down structure, a circular structure can make it difficult for employees to figure out who they report to and how they're meant to fit into the organization.

A more advanced approach to the organizations is the one for the learning organizations. Peter Drucker states that the specific knowledge that the companies have is the main asset. Moreover, it is a source of sustainable competitive advantage. The knowledge is brought by employee minds and the organizations must be projected to develop and increase their knowledge. It is the so called "intellectual capital" or "knowledge capital" and is critical for company success. The business model is a part of it. Therefore, these organizations are called "learning structures". The organizations use through them the people and systems to constantly learn from their staff and partners to constantly improve their knowledge. This way they improve the capability to adapt and change, because all the members play active role in identifying and solving problems (Drucker, 2001; Smith, 2007). In a learning organization employee could exchange freely information, cooperate with people from other units and functional specialists, as much as possible the barriers are removed. The experts in teams have the power to take decisions how to do their job. This way, through building trust and increased responsibility, the need of strong control is at low levels. The managers should give support, motivate, lead using approach of shared values and cooperation.

The learning organization is typical for an organization targeting a market with uncertainty and a variety of products may implement with success Lean Development and its principles. The second principle of Lean Development is "Amplify learning" which means that learning is key for the product success. The other interesting principle is Empower the team. This means, that the team equipped with the needed expertise and guided by a leader will make the best technical and process decisions for their tasks (Poppendieck et al, 2003). The teamwork and self-determination show that the organizational structure is more likely to be team-oriented with flat structure. Management is done by leadership and management's role is to run interference (Poppendieck et al, 2003, p.108). Another Lean approach is Lean Startup, which includes learning as an ongoing process of hypothesis-driven experiments to find the product-market fit (Ries, 2011).

\section{Organization structure for starting software companies}

The requirements for the organization and its structure are determined by the tasks needed to do and goal to achieve. The conditions under which work starting companies are these (Blank, 2013; Ries, 2011; Poppendieck, 2003):

- Limited entrepreneurial opportunities

- High uncertainty 
- Product is not clear; Requirements come through experience and may change over time

- Customer is not clear

- Limited resources - financial, material, human, informational.

- High risk of failure.

To select appropriate organization's characteristics and management approach, we can review the models for company development. The starting company will be in the first or second stage of organization development. According to the model of Larry Greiner the starting companies fit in the first or second phase of the model. The first phase is a phase of the creativity/creation. The focus is on product creation, business model definition and initial sales. The organization's structure is simple (Mintzberg), linear and centralized. The staff works in an informal environment, weak definition of broad tasks, direct control from the entrepreneurs and the results. After some growth, when the sales and number of employees grow, it comes a crisis of leadership and time for professional management. The company should go to specialization, defining rules, building management systems and hiring a manager, functional structure, first procedures created (Greiner, 2001). After a significant growth, the organization goes into next stage, which is out of our scope.

Another model of company growth is from Miller and Friesen. It is similar regarding the typical organization of a starting company - the owner is manager, informal structure, centralized, focus on innovations and development, niche strategy, processes and information flows are not developed. After that initial stage it follows a stage of formalization - functional structure, initial formalization, processes for information flow and decisions.

The model of Greiner and Miller and Friesen are general. A more specific for starting companies is the model of Adizes (Adizes, 1999) for the organizational life cycle of small and starting companies. The model suggests an ageing, decline to eventual death process - a focus on the detail, as opposed to the end result, may offer something rich to the understanding of small firms. According to Adizes, the organizations may be in one of ten stages as shown in Table 1.

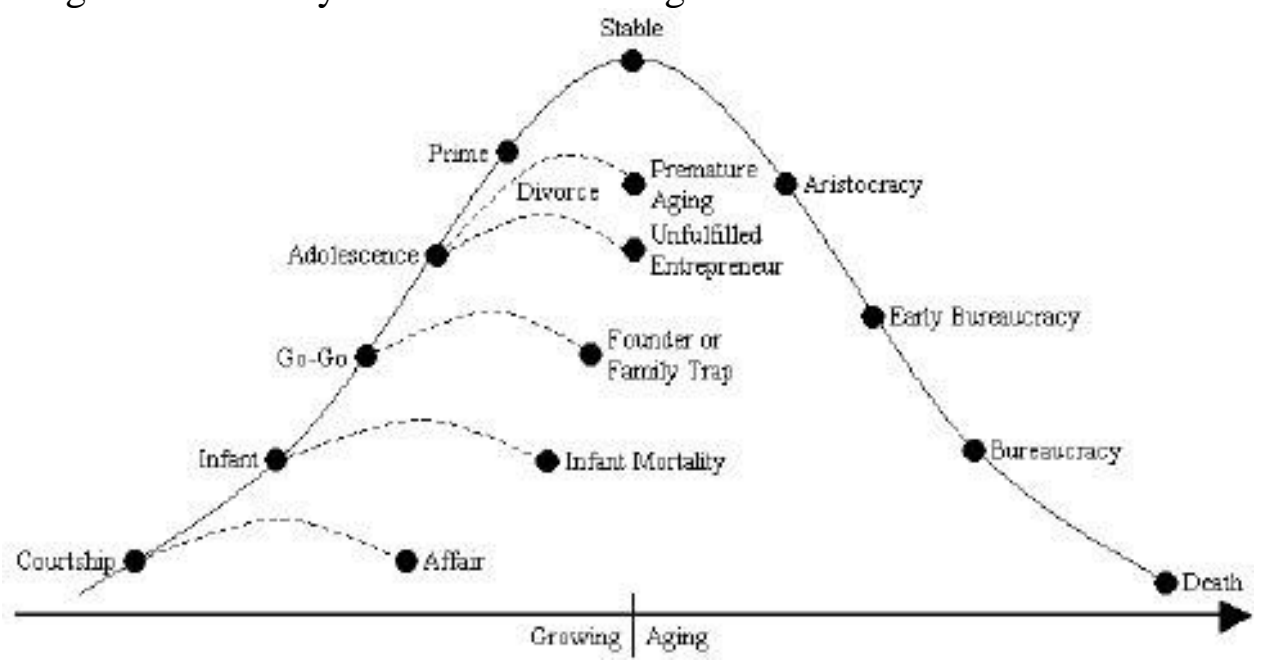

Figure 1. The Lifecycle of the small company - model of Adizes

The model is presented also on Figure 1 with the stages and possible pathology. It shows the logical progress during time and the growth of the company (if not dead in earlier stages). During this time the organization develops or should develop step by step its organization from a sole entrepreneur or a team of entrepreneurs to the moment before it becomes big, before it comes a wellfunctioning established stable organization. We think the breaking point for a company to be called "starting" is somewhere in the stage "Prime" and definitely before stage "Stable". It is the moment where the initial innovation is done, it is validated in the market and potential for growth is proven, as well as the initial crises are overwhelmed, the creativity and innovation are still on good level. The company goes from initial linear structure with (external) functional consulting and flat learning 
structure, to other appropriate structure with a stable balance of control and flexibility, like projectbased or team-based preserving the learning and innovation culture.

Table 1. List of stages of the Organizational Life Cycle Model (Adizes, 1999)

\begin{tabular}{|c|c|c|}
\hline № & Stage & $\begin{array}{ll}\text { Characteristics } \\
\end{array}$ \\
\hline 1 & Courtship & $\begin{array}{l}\text { The organization exists only as an idea. The founder must fall in love with the } \\
\text { idea before making a commitment to its execution. }\end{array}$ \\
\hline 2 & Infant & $\begin{array}{l}\text { Once the organization is born it is immediately vulnerable and in need of } \\
\text { constant care and attention to keep it going. A lack of commitment or of capital } \\
\text { may result in infant mortality. }\end{array}$ \\
\hline 3 & Go-Go & $\begin{array}{l}\text { Once the idea is working, the confidence of the founder grows. Like a child } \\
\text { who has just learned to crawl, the organization explores every opportunity. As } \\
\text { the organization grows, the energy of the founder may no longer be sufficient } \\
\text { to fuel it, resulting in the Founder or Family Trap. }\end{array}$ \\
\hline 4 & Adolescence & $\begin{array}{l}\text { After passing the Founder or Family Trap, the organization is reborn. The } \\
\text { transition to delegation and professional management is painful. Divorce } \\
\text { results where the original entrepreneurs no longer find the environment } \\
\text { fulfilling, and this may result in premature aging. Such organization has many } \\
\text { committees, meetings and some in-fighting. }\end{array}$ \\
\hline 5 & Prime & $\begin{array}{l}\text { Prime is the optimal point in the lifecycle curve. The organization achieves a } \\
\text { balance of control and flexibility. It still has room to grow, limited only by its } \\
\text { ability to attract and train enough skilled people. }\end{array}$ \\
\hline 6 & Stable & $\begin{array}{l}\text { The Stable stage marks the beginning of the Aging process. The company is } \\
\text { still strong, but is starting to lose the flexibility, creativity and innovation. The } \\
\text { number of meetings and committees starts to increase. }\end{array}$ \\
\hline 7 & Aristocracy & $\begin{array}{l}\text { The organization is focused on how things get done, and organizational } \\
\text { protocol and tradition dominate. Challenges to the status quo are frowned } \\
\text { upon, thus stifling innovation. The conflicts are swept under the carpet. }\end{array}$ \\
\hline 8 & $\begin{array}{l}\text { Early } \\
\text { Bureaucracy }\end{array}$ & $\begin{array}{l}\text { Early Bureaucracy is characterized by witch-hunting. The writing is on the } \\
\text { wall for the organization, and each area seeks evidence to blame other area. } \\
\text { The paranoia freezes the organization. Energy is spent on in-fighting. }\end{array}$ \\
\hline 9 & Bureaucracy & $\begin{array}{l}\text { The purpose of the Bureaucracy is to support its continued existence. The } \\
\text { internal systems acquire a life of their own. The organization becomes } \\
\text { dissociated with its original purpose. }\end{array}$ \\
\hline 10 & Death & $\begin{array}{l}\text { Death occurs as commitment to the organization dissipates. Clients desert, } \\
\text { followed by employees, until nothing remains }\end{array}$ \\
\hline
\end{tabular}

\section{Conclusion}

The article's goal is achieved with a review of the organizational aspects for starting software company. The terms starting software company, product, software product, business model and organization are defined. A list of theoretical organizational structures is described. Then, management theories were reviewed with notes for micro and small companies, as well as with the stages of development. The article is useful as a summary for starting software company.

\section{References}

1. Adizes, I., (1999) Corporate Lifecycles: How and why Corporations Grow and Die and What to do about it. Prentice Hall, London

2. Blank, S. (2013) The Four Steps to the Epiphany. K\&S Ranch Publishing.

3. Booth, S. (1993) Crisis Management Strategy: Competition and Change in Modern Enterprises. 
Routledge.

4. Burgelman, R. (2004) Strategic management of technology and innovation. 4th ed., Boston: McGraw-Hill Irwin.

5. Daft, R. (2002) Management. Sixth ed. Thompson South-Western.

6. Donnelly, J., Gibson, J. and Ivanchevich, J. (1992) Fundamentals of Management. Eight ed. Boston, IRWIN.

7. Drucker, P. The Theory of the Business. Harvard Business Review, September 1994, [Online] Available from (https://hbr.org/1994/09/the-theory-of-the-business) [Accessed: 01/10/2019].

8. Drucker, P. (2001) The Essential Drucker: In One Volume the Best of Sixty Years of Peter Drucker's Essential Writings on Management. 1st ed. HarperBusiness.

9. Eskenazi, A. and Maneva, N., Softuerni Tehnologii. 2nd ed. Sofia: KLMN, 2006.

10. European Commission. What is an SME? [Online] Available from (https://ec.europa.eu/growth/ smes/business-friendly-environment/sme-definition_en/) [Accessed: 01/10/2019].

11. Greiner, L. (1972) Evolution and Revolution as Organizations Grow. Harvard Business Review, $\mathrm{N}: 4$

12. Griffin, R. (1990) Management. Third edition. Houghton Mifflin Company.

13. Katila, R., Chen, E. and Piezunka, H. (2012) All the right moves: How entrepreneurial firms compete effectively. Strategic Entrepreneurship Journal, Volume 6 Issue 2, pp.116-132.

14. Kreitner, R. (2009) Management. Fifth ed. Houghton Mifflin Company.

15. Magretta, J. (2002) Why Business Models Matter. Harvard Business Review. 2002 May Issue. [Online] Available from: (https://hbr.org/2002/05/why-business-models-matter) [Accessed: 01/10/2019].

16. Maurya, A. (2012) Running lean: iterate from plan A to a plan that works. The lean series (2nd ed.). Sebastopol: O'Reilly.

17. Morris, L. (2003) Business Model Warfare. Pensylvania, USA: Ackoff Center for the Advancement of Systems Approaches (A-CASA). 2003.

18. Mullins, J. and Komisar, R. (2013) Getting to Plan B: Breaking Through to a Better Business Model. Harvard Business Press.

19. Osterwalder, A. and Pigneur, Y. (2010) Business Model Generation: A Handbook for Visionaries, Game Changers, and Challengers. 1. Aufl. Hoboken, NJ: John Wiley and Sons.

20. Panayotova, G., Dimitrov, G.P., Petrov, P., \& Os, B. (2016) Modeling and data processing of information systems. 3rd International Conference on Artificial Intelligence and Pattern Recognition, AIPR 2016, pp.154-158.

21. Petrov, P., Krumovich, S., Nikolov, N., Dimitrov, G., \& Sulov, V. (2018) Web technologies used in the commercial banks in Finland. ACM International Conference Proceeding Series, CompSysTech'18: 19-th International Conference on Computer Systems and Technologies, pp.94-98.

22. Poppendieck, M. and Poppendieck, T. (2003) Lean Software Development: An Agile Toolkit. Addison-Wesley Professional.

23. Ries, E. (2011) The Lean Startup. Crown Publishing Group.

24. Robins, S. and De Cenzo, D. (2008) Fundamentals of Management: Essential concepts and applications, Prentice-Hall.

25. Santos, F. and Eisenhardt, K. (2009) Constructing markets and shaping boundaries: entrepreneurial power in nascent fields. Academy of Management Journal, 52(4), pp.643-671.

26. Scarborough, N. (2013) Essentials of Entrepreneurship and Small Business Management, 7.Aufl., New Jersey, USA: Prentice Hall PTR.

27. Smith, M. (2007) Fundamentals of Management. McGraw-Hill.

28. Tapscott, D., Ticoll, D. and Lowy, A. Digital Capital: Harnessing the Power of Business Webs. Ubiquity. 2000.

29. Timmers, P. Business models for electronic markets. Electronic Markets, 1998, 8(2), pp.3-8. 